\section{Öğrenciler için Eğitim Cüzdanı: Öğrencilerin Eğitim Etkinliklerinin Blokzinciri Üzerinde Paylaşılması*}

\author{
Mustafa Tanrıverdi ${ }^{1}$ Mevlüt Uysal ${ }^{2}$ \\ Mutlu Tahsin Üstündağ ${ }^{3}$
}

Türk Eğitim Bilimleri Dergisi

Makale Türü: Araştırma

Makale Geliş Tarihi: 07.11.20

Makale Kabul Tarihi: 18.12.20

Makale Yayın Tarihi: 28.12.20

ORCID: 0000-0003-3710-4965,

0000-0002-6934-4421,

0000-0001-6198-2819

\title{
Öz
}

Son zamanlarda hayatımıza hızla giren blokzinciri teknolojisi sayesinde finans, kamu hizmetleri, sağlık ve tedarik zinciri gibi alanlarda uygulamasını gördüğümüz etkili çözümler geliştirilmiştir. Sınırlı sayıda da olsa eğitim alanında da blokzinciri konulu çalışmalara rastlanmaktadır. Yapılan çalışmalar ve yayımlanan raporlarda öğrenci etkinliklerinin, eğitim içeriklerinin, ders kredilerinin, sertifika bilgilerinin, harç ve burs ödemelerinin blokzinciri üzerinde saklanabileceği ve paylaşılabileceği ifade edilmektedir. Blokzinciri teknolojisi şeffaf ve merkezi olmayan dağıtık yapısı sayesinde üçüncü taraf ve merkezi kurumları devreden çıkarabilmekte ya da birbiri ile ilişkili aynı seviyedeki kurumlar arasında güvenli ve şeffaf bir veri paylaşımı imkânı sunmaktadır. Bu çalışma kapsamında örgün eğitim, uzaktan eğitim ve sertifika eğitimi hizmeti veren eğitim kurumları arasında blokzinciri sisteminin kurulmasına ilişkin bir çalışma yapılmıştır. Bu uygulamalı araştırma sayesinde zincire katılan eğitim kurumlarından hizmet alan öğrencilerin etkinlikleri blokzinciri üzerinde tutulabilmekte ve her bir kurum öğrencilerin eğitim etkinliklerine ve böylelikle hazırbulunuşluk seviyelerine erişebilmektedir. Eğitim kurumlarının yanı sıra öğrenciler de kendi etkinliklerine ulaşabileceklerdir. Başka bir deyişle öğrenciler için blokzinciri üzerinde eğitim cüzdanları oluşturulmuş olacaktır. Geliştirilen uygulama ile eğitim kurumlarının blokzinciri üzerinden veri paylaşımı yapabilmesi ve öğrencilerin eğitim cüzdanlarını görüntüleyebilmeleri sağlanmıştır. Bu çalışma kapsamında blokzincirine katılacak eğitim kurumları için blokzinciri sisteminin kurulumu, kurulan blokzincirlerinin birbirine bağlanması, kurumların bilgi sistemlerinin blokzinciri sistemi ile entegrasyonunun sağlanmasına ilişkin örnek uygulama ve örnek senaryolar üzerinden karşılaştırmalı bilgi sunumu yapılmıştır.

Anahtar Sözcükler: Blokzinciri, Eğitim cüzdanı, Eğitim teknolojileri

\footnotetext{
Abstract

Recently, effective solutions have been developed in the fields of finance, public services, health, and supply chain, thanks to the blockchain technology that has entered our lives. Although limited, some studies on blockchain are also found in the field of education. It is stated in the studies and published reports that student activities, educational contents, course credits, certificate information, tuition, and scholarship payments can be stored and shared on the blockchain. Thanks to its transparent and distributed structure, blockchain technology enables third party and central institutions to disengage or to provide secure and transparent data sharing between institutions at the same level. Within the scope of this study, it was aimed to establish a blockchain system between formal education, distance

* Bu çalışma 2-4 Mayıs 2019 tarihleri arasında düzenlenen 13. Uluslararası Bilgisayar ve Öğretim Teknolojileri Sempozyumu'nda özet bildiri olarak sunulmuştur.

${ }^{1}$ Mustafa Tanrıverdi, Öğr. Gör. Dr., Gazi Üniversitesi, Ankara, mustafatanriverdi@gazi.edu.tr

2 Mevlüt Uysal, Öğr. Gör. Dr., Gazi Üniversitesi, Ankara, mevlutuysal@gazi.edu.tr

${ }^{3}$ Mutlu Tahsin Üstündağ, Doç. Dr., Gazi Üniversitesi, Ankara, mutlutahsin@gazi.edu.tr
} 
education, and educational institutions that provide certificate training services. Thanks to this applied research, the activities of the students who received service from the educational institutions participating in the chain will be kept on the blockchain, and each institution will have access to the educational activities of the students and thus the levels of their readiness. In addition to educational institutions, students will be able to reach their own activities. In other words, educational wallets will be created on the blockchain for students. With the developed application, it was ensured that educational institutions could share data via blockchain, and students could view their educational wallets. Within the scope of this study, the implementation of the blockchain system for the educational institutions to be included in the blockchain, the connection of the established blockchains to each other, the recommendations to implement the integration of the information systems of the institutions with the blockchain system, and the comparative information were presented on the sample scenarios.

Keywords: Blockchain, Educational wallet, Educational technologies

\section{Giriş}

İlk kez kripto paralar ile hayatımıza giren blokzinciri teknolojisi son zamanlarda medya, araştırmacılar, ulusal ve uluslararası kuruluşlar tarafından büyük ilgi görmektedir. Blokzinciri dağıtık, şeffaf ve güvenilir yapısı sayesinde yetki ve sorumlulukların merkezi yapılar yerine paydaşlar tarafından yönetilmesine olanak vermektedir. Blokzinciri sayesinde insanlar ve kurumlar üçüncü taraf aracılara ihtiyaç duymadan verilerini şeffaf ve güvenli bir şekilde paylaşabilmektedir. Blokzinciri teknolojisi sunduğu fırsatlar, ortaya çıkış şekli ve hızı bakımından 20. yy. sonlarında ortaya çıkan internet kavramına benzemektedir. Allied Market Research tarafından yayımlanan raporda blokzinciri piyasasının 2016 yılında 228 milyon dolar olduğu ve 2023 yılına kadar 5.4 milyar dolar seviyelerine ulaşabileceği belirtilmiştir (“Blockchain Distributed Ledger Market Size by Type, End-User," 2017). Blokzinciri teknolojisinin sektördeki bu popülerliği akademik çalışmalarda da görülmektedir. Çok kısa zaman önce alanyazında blokzinciri konulu bir çalışmaya rastlamak çok zor iken şuan bu konuyla ilgili birçok çalışmanın bulunduğu ve sayılarının giderek arttığı görülmektedir (Anascavage ve Davis, 2018).

Günümüzde kurumların işleyiş̧ini ve bireysel alışkanlıkları değiştiren bilgi ve iletişim teknolojileri gelişimlerini hızla devam ettirmektedir. Kurumların gelişen teknolojiye ayak uydurması ve bunu iş süreçlerine dâhil etmesi önemlidir. Bu bağlamda farklı alanlarda hayatı kolaylaştıran birçok blokzinciri uygulamasına rastlamak mümkündür. Bu çalışmada örgün eğitim, uzaktan eğitim, sertifika eğitimi gibi hizmetler sunan eğitim kurumları arasında blokzinciri sisteminin kurulmasına ilişkin bir uygulama geliştirilmiştir. Her bir eğitim kurumu için blokzinciri kurulması ve kurulan zincirlerin birbirine bağlanması süreçleri hakkında bilgi verilmiştir. Gerekli güvenlik ve veri paylaşımı kuralları belirlendikten sonra örnek eğitim uygulaması olarak kurulan Moodle uygulamasının blokzinciri uygulaması ile entegrasyonu sağlanmış ve kullanıcı arayüzünde gerekli düzenlemeler yapılmıştır. Moodle uygulamasının yanı sıra öğrenci etkinliklerinin listelendiği bir sertifika yönetimi uygulaması 
ve blokzinciri uygulaması arasında örnek bir entegrasyon senaryosuna da verilmiştir. Bu şekilde farklı eğitim kurumları tarafından sınav sonucu, ders içerikleri, sertifika, ödev gibi eğitim içeriklerinin ortak bir blokzincirine aktarılması sağlanmıştır. Aktarılan eğitim içeriklerine hem öğrenciler hem de paydaş eğitim kurumları erişebilmektedir. Bu sayede oluşturulan eğitim cüzdanları sayesinde öğrenciler kurumlardan bağımız olarak kendi eğitim faaliyetlerine erişebilmektedirler. Eğitim kurumları ise bu eğitim cüzdanları sayesinde öğrencilerin hazırbulunuşluk seviyeleri hakkında bilgi edinebilecek ve ileride geliştirilecek eğitim programları için bu verilerden faydalanabilecektir. Sonraki bölümlerde geliştirilen örnek uygulama hakkında ayrıntılı bilgilere ve ekran görüntülerine yer verilmiştir.

Çalışmada ayrıca blokzinciri kavramı, özellikleri, çalışma prensibi hakkında ayrıntılı bilgi verilmiş ve eğitim alanında yapılmış çalışmalardan bahsedilmiştir.

\section{Blokzinciri Tanımı ve Özellikleri}

Kriptografiden faydalanarak verilerin güvenli bir şekilde blok yapısında kaydedilmesi üzerine ilk çalışma Haber ve Stornetta (1991) tarafından yapılmıştır. Blokzinciri tanımı ilk kez gerçek Satoshi Nakamoto takma isimli bir kişi ya da grubun "Bitcoin: A Peer-to-Peer Electronic Cash System" adlı makalesinde kullanılmıştır (Nakamato, 2008). Bu makalede merkez bankaları ve hükûmetler gibi merkezi otoritelerden bağımsız bir elektronik para olan Bitcoin tanıtılmıştır. Bitcoin, daha sonra Ethereum (Wood, 2014) ve Ripple (“Ripple," t.y.) gibi blokzinciri tabanlı birçok elektronik paranın geliştirilmesinin önünü açmıştır. Elektronik paraların değerinin son yıllarda çok hızlı artması sayesinde blokzinciri kavramı popüler hâle gelmiş ve blokzinciri konulu çalışmalarda büyük bir artış görülmüştür.

Alanyazında birçok blokzinciri tanımına rastlamak mümkündür. Reyna, Martin, Chen, Soler ve Diaz (2018) blokzincirini yapılan veri işlemlerinin güvenirliğinin ağdaki paydaşlar tarafından sağlandığı bir veri yapısı olarak tanımlamıştır. Beck (2018)' e göre ise blokzinciri, zincirdeki çok sayıda paydaşın şeffaf, güvenli ve doğrulanabilir veri işlemlerin yapılmasını sağlayan merkezi olmayan bir veri yapısıdır. Literatürdeki diğer tanımları da incelendiğinde, blokzinciri için katılımcı paydaşlara ait verilerin internet üzerinden kriptografik şifreleme ve doğrulama algoritmaları sayesinde şeffaf ve güvenli bir şekilde, merkezi olmayan dağıtık bir yapıda yönetilmesi olarak genel bir tanım yapılabilir. Bilişim teknolojileri tarafından bakıldığında, blokzinciri merkezi olmayan uzlaşma yöntemleri, kriptografik algoritmalar ve dağıtık, şeffaf ve değiştirilemez bir veritabanının birleşimi olarak tanımlanabilir.

Blokzincirinin avantajları genel olarak aşağıdaki gibi sıralanabilir (Gatteschi, Lamberti, Demartini, Pranteda ve Santamaria, 2018): 
- Blokzinciri ağının bir sahibi yoktur, herhangi bir düğüm zincirden çıkarsa ağ çalışmaya devam eder.

- Zincirdeki tüm verinin bir kopyası katılımcı paydaşlar tarafından kaydedilir ve bu verilerin güncelliği sağlanmak zorundadır. Paydaşlar tüm veriye erişebilir ve yapılan işlemleri görebilir. Verilerin bu şekilde saklanması sayesinde veri kaybı ve veri tahribatı önlenir.

- Dijital imza ve mutabakat işlemleri sayesinde merkezi bir otoriteye ya da üçüncü taraf uygulamalara ihtiyaç ortadan kaldırılarak ve paydaşların birbirine güvenmesini sağlanır.

- Ağda bulunan düğümler diğer düğümlerin yaptığı işlemleri görebilir, bu sayede şeffaflık sağlanmış olur.

- Blokzincirinde bulunan bir verinin değiştirilmesi ya da silinmesi mümkün değildir.

- Akıllı sözleşmeler sayesinde belirli faaliyetler otomatikleştirilebilir.

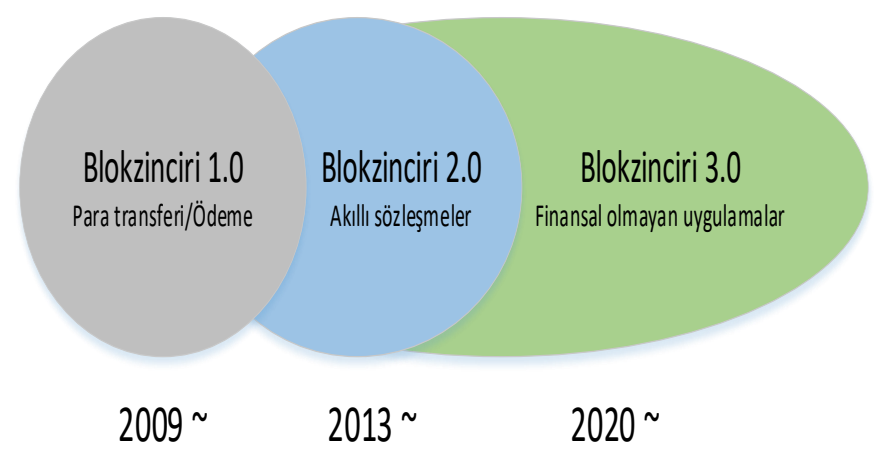

Şekil 1. Blokzincirin Gelişimi (Cheng, Lee, Chi ve Chen, 2018)

Günümüzde blokzincirinin gelişimi Şekil 1'deki gibi üç evre halinde tanımlanabilir (Efanov ve Roschin, 2018; Swan, 2015; Zhao, Fan ve Yan, 2016; Cheng, Lee, Chi ve Chen, 2018). Dijital para evresi olarak da adlandırılan Blokzinciri 1.0, varlık yönetimi, para transferi ve dijital ödeme gibi hizmetleri sunan kripto paraları olarak ifade edilebilir. Blokzinciri 2.0 dijital ekonomi olarak ifade edilebilir ve dijital ödemeler ve para transferi işlemlerin ötesinde, krediler ve ipotekler, hisse senetleri, tahviller, vadeli işlemler ve sözleşme gibi bankacılık uygulamalarının dijital olarak yönetilmesini sağlar. Genelde merkezi bir yapı ya da üçüncü taraf uygulamalara güven gerektiren bu işlemlerin blokzinciri ağı içerisinde oluşturulan ve çalıştırılabilen akıllı sözleşmeler (smart contracts) ile yönetilmesi sağlanmıştır. Blokzinciri 3.0 dijital toplum ifade edilebilir ve dijital para, varlık yönetimi, akıllı sözleşme içeren uygulamalar dışında yönetim ve denetim, eğitim, sağlık, iletişim gibi alanları da kapsamaktadır (Burgess, 2015). Son yıllarda sıkça duyulan dijital kimlik, elektronik hasta verilerinin yönetimi, siber güvenlik, nesnelerin interneti gibi alanlarda yapılmış blokzinciri konulu çalışmalar da Blokzinciri 3.0 kapsamında düşünülebilir (Cai ve Zhu, 2016).

Blokzinciri sistemleri dışarıya açık olma ve yönetim durumlarına göre Genel (Public) Blokzinciri, Özel (Private) Blokzinciri ve Konsorsiyum (Consortium) Blokzinciri olmak üzere üç 
kategoride incelenmektedir (Buterin, 2015; Puthal, Malik, Mohanty, Kougianos ve Das, 2018). Genel Blokzinciri, herhangi bir izin gerektirmeden isteyen kurumların ya da kişilerin katılımına, kayıt eklemesine, kayıtları görmesine ve madencilik yapmasına imkân veren açık bir ortam sunmaktadır. Bu tür blokzincirleri, herhangi bir izin ya da kısıtlama içermediği için izinsiz blokzinciri olarak da adlandırılır. Bir kişi ya da grup tarafından yönetilen, bir ya da birkaç organizasyon arasında paylaşım ve veri alışverişini sağlayan blokzinciri yapıları Özel Blokzinciri olarak adlandırılmaktadır. Ağa bir paydaşın katılımı ve erişimi, ağı yöneten grup tarafından belirlenen kurallara göre yapılmaktadır. Konsorsiyum Blokzincirinde, blok doğrulama ve uzlaşma işlemlerinde tek bir organizasyonun yerine önceden belirlenmiş bir grup paydaşın karar verici olarak yer alması sağlanır. Bu tür blokzincirleri kısmen özel ve izinli blokzinciri olarak da ifade edilebilir. Kimlerin ağa katılabileceğine ve kimlerin madencilik yapabileceğine, kimlerin verileri görebileceğine önceden belirlenen yetkili paydaşlar karar vermektedir.

\section{Blokzinciri Mimarisi}

Blokzinciri, gerçekleşen tüm işlem kayıtlarının dağıtık olarak tutulduğu sıralı bloklardan oluşmaktadır (Chuen, 2015). Şekil 2' de blokzinciri yapısının bir örneği gösterilmektedir. Zincirdeki her bir blok önceki bloğun özet değeri (hash value) taşımaktadır.

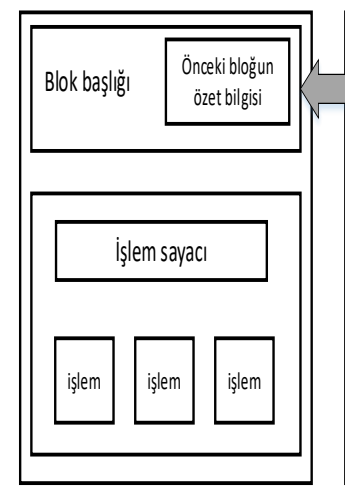

Bloki-1

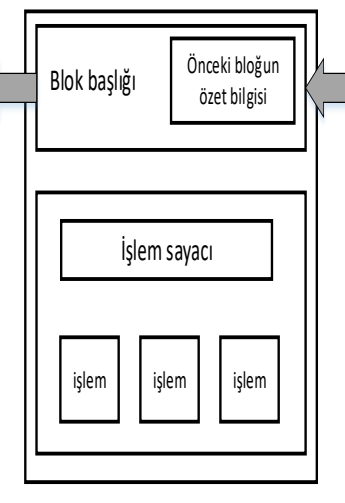

Bloki

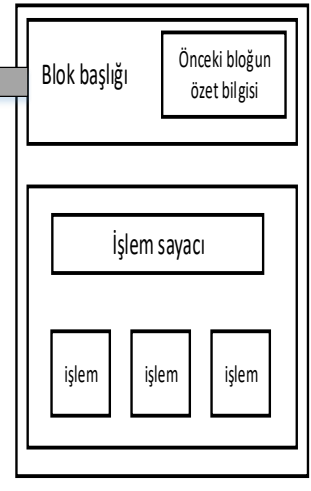

Bloki+1

Şekil 2. Blokzinciri Yapısı (Tanrıverdi, Uysal ve Üstündağ, 2019)

Bir blok Şekil 3'te gösterildiği gibi bir başlık ve bir gövdeden oluşmaktadır. Blok gövdesinde yapılan işlem kayıtları bulunmaktadır. Blok başlığında ise hangi blok kurallarının uygulanacağını belirleyen blok versiyonu, bloktaki tüm işlem kayıtlarının özet değeri olarak Merkle ağaç kökü özeti, zaman damgası bilgisi özet değeri hesaplamaları için gerekli Nbit ve Nonce değerleri ile birlikte önceki bloğun özet bilgisi değeri tutulmaktadır. Burada Nbit geçerli bir blok değeri için eşik değeri içermektedir. Nonce ise genellikle 0 ile başlayan ve her bir hesaplama için artan 4 byte boyutunda bir alandır. 


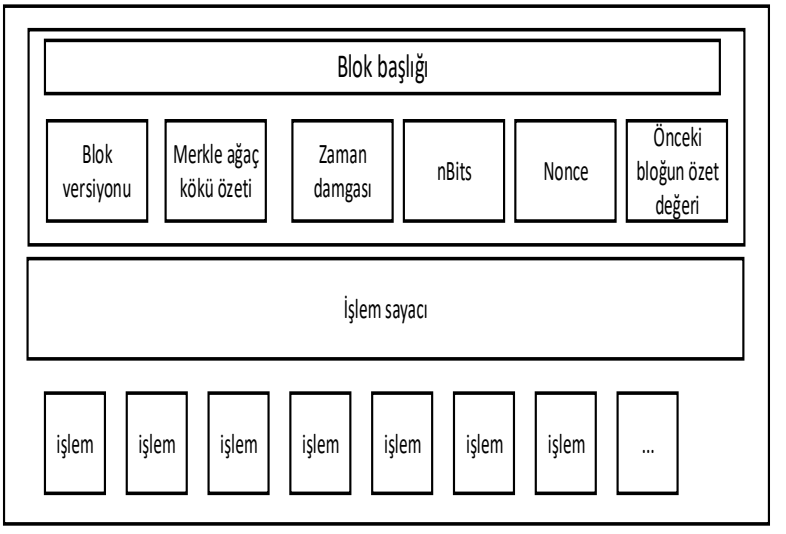

Şekil 3. Blok Yapısı (Tanrıverdi, Uysal ve Üstündağ, 2019)

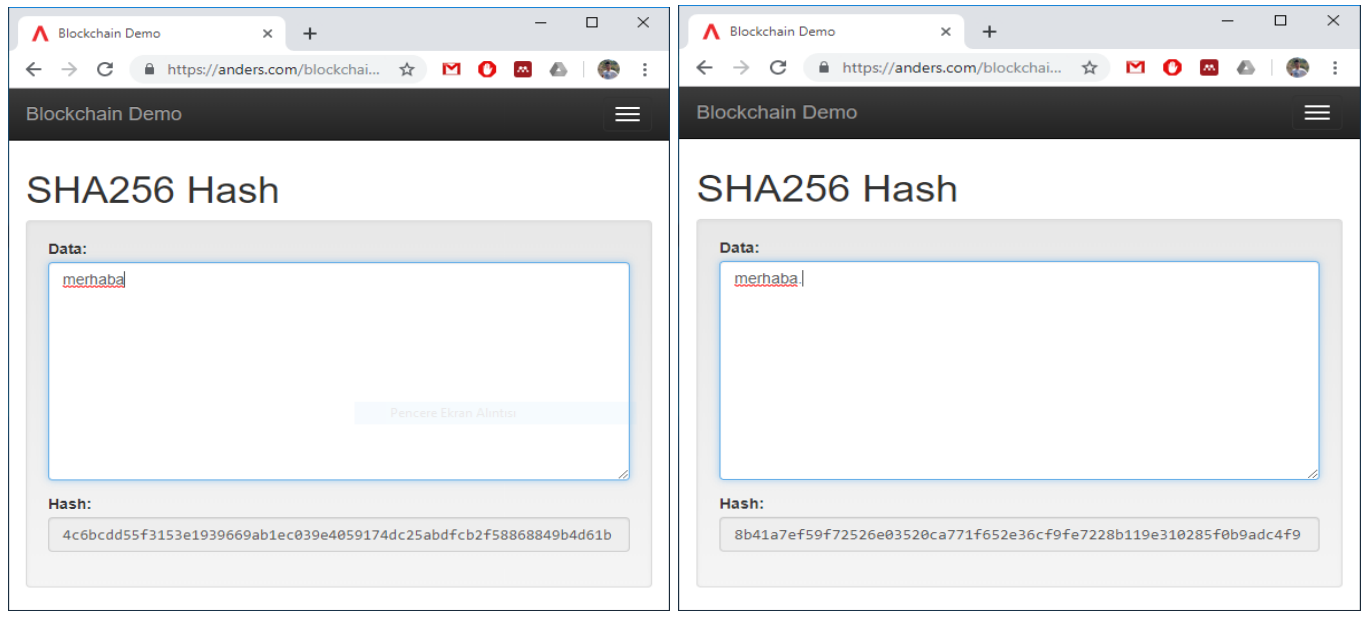

Şekil 4. Özet Değeri Hesaplanması (“Blockchain Demo,” t.y.)

Blokzincirinde blokta yer alan verilerin üzerinde değişiklik yapılıp yapılmadığı özet değeri ile tespit edilmektedir. Her verinin hesaplanan özet bilgisi değeri birbirinden farklı olmaktadır. Şekil 4'te görüldüğü üzere "merhaba" metin değerinin özet değeri “4c6bcdd55f3153e1939669ab1ec039e4059174dc25abdfcb2f58868849b4d61b" olarak hesaplanmıs, "merhaba." metin değerinin özet değeri ise “8b41a7ef59f72526e03520ca771f652e36cf9fe7228b119e310285f0b9adc4f9” olarak hesaplanmıştır. Görüldüğü gibi iki metin arasında tek karakter fark olmasına rağmen bu metinlerin özet değerleri birbirinden tamamen farklıdır.

Blokzinciri yapısında blokların yapısı ve özet değeri ile birbirine olan bağlantısının daha iyi anlaşılması için Şekil 5'te görülen örneğe yer verilmiştir. Şekilde her bloğun gövde kısmında yapılan işlemlere ait örnek veriler bulunmaktadır. Blok belirli bir işlemden sonra veri kayıt kapasitesini doldurmakta ve özet değeri hesaplanarak zincirde yayımlanmaktadır. Bu şekilde bir blok için hesaplanan özet değeri ilgili bloğun içerisinde bulunan işlem kayıtları üzerinden hesaplanmaktadır. Yeni bir blok oluşturulurken bir önceki bloğun özet değeri ile ilişkilendirilmek zorundadır. Şekilde görüldüğü gibi ilk bloğun önceki blok özet değeri alanında “000....” değeri görülmektedir. Daha 
sonraki bloklarda ise bu alanda bir önceki bloğun hesaplanan özet değeri yer almaktadır. Zincirde yer alan bir bloğun verilerinde bir değişiklik yapılırsa ilgili bloğun özet değeri değişecektir. Bunun sonucu olarak bir sonraki zincir ile özet değerleri üzerinden kurulan ilişki sağlanamayacak ve zincirin veri bütünlüğü bozulmuş olacaktır.

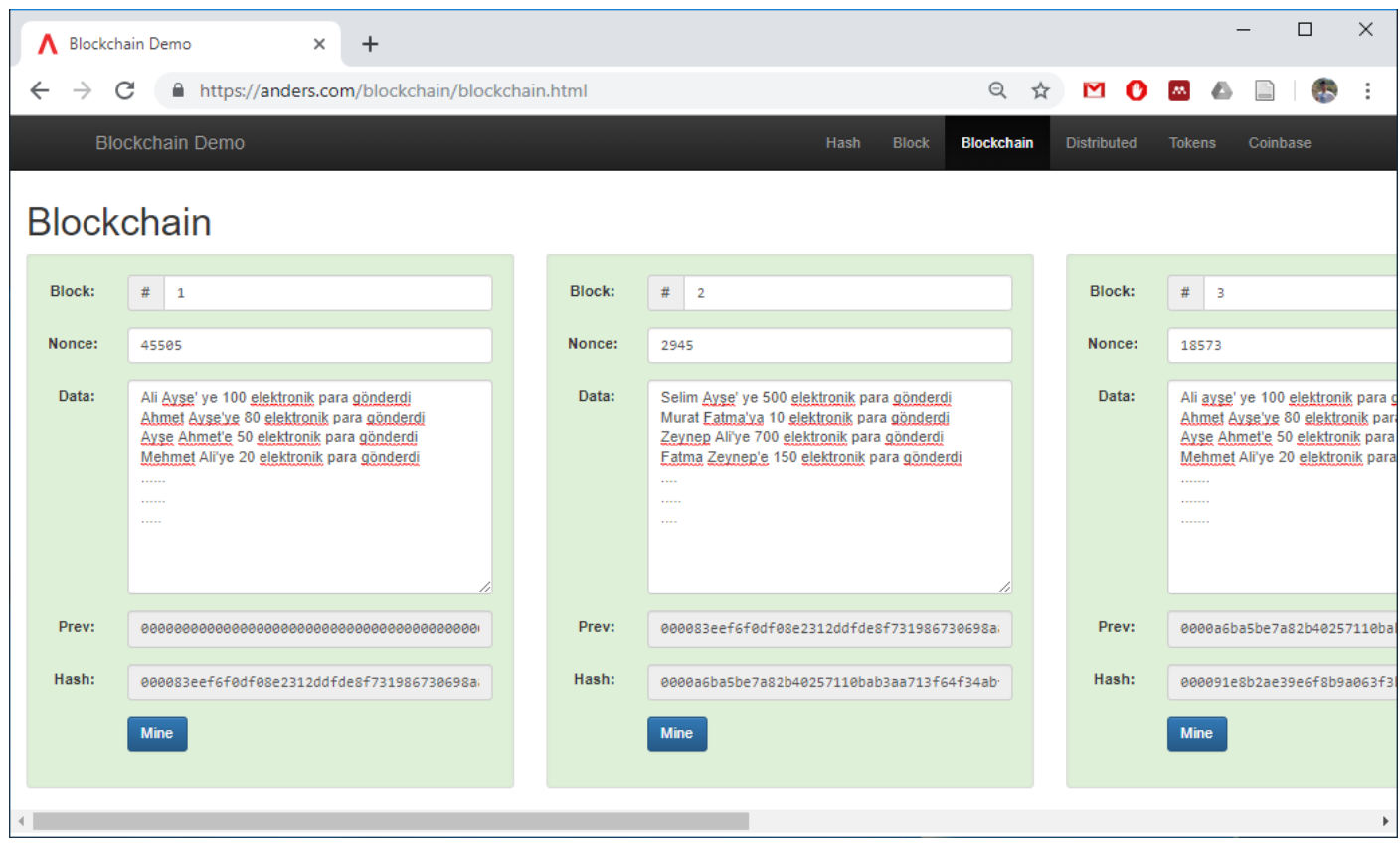

Şekil 5. Blokzincirinde Blok ve Özet Değerleri (“Blockchain Demo," t.y. )

\section{Eğitimde Blokzinciri Uygulamaları}

Bazı araştırmacılar blokzinciri teknolojisinin hala çok yeni bir çalışma alanı olarak kabul etmiş, her sektörün bu teknolojiden yüksek beklentileri olduğunu belirtmiş ve blokzinciri uygulamalarının adaptasyonu bağlamında bu sektörlerin özelliklerinin incelenmesi gerektiğini ifade etmiştir (Wang, Chen ve Xu, 2016; Yli-Huumo, Ko, Choi, Park ve Smolander, 2016). 2016 ve 2017 yillarından sonra blokzinciri kavramının hızla popüler hâle gelmesi sayesinde blokzinciri konulu araştırmaların ve uygulamaların sayısında önemli bir artış görülmüştür. Finans, kamu hizmetleri, sağlık ve tedarik zinciri gibi alanlar etkili çözümler sunan blokzinciri konulu çalışmalar bulunmaktadır.

Eğitim alanında da blokzinciri teknolojisi sayesinde bazı zorlukların ortadan kaldırılabileceği düşünülmektedir. İngiltere' de bulunan Open University tarafından yayımlanan “Innovating Pedagogy 2016" adlı raporda eğitim alanında blokzinciri kullanımının 4 yıldan uzun bir süre içerisinde yaygınlaşacağı belirtilmiştir (Sharples, De Roock, Ferguson, Gaved, Herodotou, Koh, Wong, 2016). Raporda blokzinciri üzerinde eğitim içeriklerinin, ders kredilerinin ve sertifika bilgilerinin dağıtık yapıda saklanabileceği ve paylaşılabileceği ifade edilmiştir.

Avrupa Komisyonu 2017 yılında "Blockchain in Education" adlı bir rapor yayımlamıştır (Camilleri, 2017). Bu raporda blokzinciri teknolojisinin sertifikasyon, hayat boyu öğrenme, harç ücreti 
ödemeleri ve öğrencilere burs ödemeleri gibi alanlarda kullanım senaryoları önerilmiştir. Örnek senaryo olarak sertifika, diploma, transkript gibi belgelerin blokzinciri üzerinde saklanması halinde bu belgelerin kaybolması ve tahrip edilmesinin önüne geçilebileceği ifade edilmiştir. Bu sayede öğrenciler ve üçüncü şahıslar bir sertifikanın doğrulamasını blokzinciri üzerinden yapabileceklerdir. Blokzinciri yapısı gereği bütün zincir verisinin bir kopyası her bir paydaş tarafından saklanması gerekmektedir. Sertifika alınan eğitim kurumunun bilgi sisteminin çökmesi ya da kapanması durumunda bile o kurumun ürettiği tüm sertifikalara blokzinciri sistemi üzerinden erişmek mümkün olacaktır. Raporda ayrıca akıllı sözleşmeler sayesinde herhangi bir aracıya ihtiyaç duymadan öğrencilere burs, kupon gibi ödemelerin yapılabileceği ve öğrencilerin eğitim ödemelerini elektronik para birimleri ile alınabileceği ifade edilmiştir.

Turkanovic, Holbl, Kosic, Hericko ve Kamisalic (2018) Avrupa Komisyonu raporunda yer alan senaryoları hayata geçirebilecek EduCTX adlı uygulamayı geliştirmiştir. EduCTX uygulaması sayesinde yükseköğretim öğrencilerinin tamamladıkları ders kredileri blokzinciri üzerinde ağdaki tüm kurumlar tarafından ECTS (European Credit Transfer and Accumulation System) uyumlu olarak saklanmaktadır. Bu sayede öğrenciler farklı kurumlarda tamamladıkları ders kredilerini blokzincirindeki hesaplarında görebilmektedir. Ayrıca katılımcı tüm yükseköğretim kurumları başvuru, belge doğrulama gibi işlemleri blokzinciri üzerinden yönetebilmektedir.

Cheng, Lee, Chi ve Chen (2018) diploma ve sertifikaların kâğıda basılı olarak üretilmesi yerine blokzinciri üzerinde tutulmasına ilişkin bir çalışma yapmıştır. Sunulan sistem sayesinde kâğıda basılan belgenin kaybolması, tahrip edilmesi ya da üzerinde değişiklik yapılabilmesinin önüne geçilmiştir. Blokzincirinin sunduğu dijital doğrulamalar sayesinde iş başvurusu yapılan firmalara ya da eğitim kurumlarına öğrencilerin belgelerini doğrulama imkânı sağlanmıştır. Huynh, Tru Huynh, Pham ve Khoa Ngo (2018) da sertifikaların blokzinciri üzerinde dijital olarak saklanması ve doğrulanmasına imkân veren bir çözüm sunmuştur.

Shen ve Xiao (2018), ara sınav ve final gibi sınavların şeffaf, adil ve sonradan değiştirilemez olması gerektiğini ifade etmişlerdir. Bunun için sınav sorularının, öğrenci cevaplarının ve sınav sonuçlarının bir konsorsiyum blokzinciri üzerinde tutulmasına olanak veren bir çözüm önerilmiştir. Sınav soruları ve verilen cevapların blokzinciri üzerinde tutulması ve bu kayıtların öğrencilerin anonim kimlikleri üzerinden oylanması ve kabul edilmesi gerektiği ifade edilmiştir. Bu sayede öğrencilerin gerçek kimlik bilgileri gizli tutularak sınav süreçlerinin şeffaf ve değiştirilemez olması sağlanabilmiştir.

$\mathrm{Bu}$ alanda yapılmış çalışmalar incelendiğinde ders kredi bilgilerinin blokzinciri üzerinde tutulması, diploma ve sertifikaların blokzinciri üzerinden dijital olarak doğrulanması, ara sınav ve final gibi notların şeffaf ve değiştirilemez olması için blokzinciri ağında tutulması gibi çözümler 
üretildiği görülmüştür. Bu çalışmalarda sunulan blokzinciri çözümleri birçok eksikliği gidermiş olmasına rağmen genel olarak merkezi uygulamalar olarak kullanılmıştır. Bu uygulamaların merkezi bir yapı tarafından geliştirilmesi ve yürütülmesi gerekmektedir. Bu çalışmada önerilen eğitim cüzdanı uygulaması merkezi bir yapı yerine eğitim kurumlarının birbirlerine güvenmesi üzerine geliştirilmiştir. Herkese açı olmayacak bu tür blokzinciri sistemlerinin yapısı gereği gibi kurul ya da grup tarafından yönetilmesi gerekmektedir. Önerilen uygulama üniversiteler, sürekli eğitim merkezleri, halk eğitim merkezleri, özel kurs ve sertifika merkezleri gibi eğitim kurumları özel blokzincirine katılabilmesine olanak sağlamaktadır. Zincire katılan eğitim kurumları öğrencilerin sertifika, başarı belgesi, proje notu gibi bilgilerini blokzincirine aktarabilmekte ve uygulama üzerinde veri sağlayıcı, veri deposu ve veri doğrulayıcı olarak görev yapmaktadır. Bu alanda yapılan çalışmalardan farklı olarak zincire katılmak isteyen eğitim kurumu blokzinciri düğümü oluşturup, kendi eğitim uygulaması ile blokzinciri arasındaki entegrasyonu sağlayabilecektir.

\section{Önerilen Uygulama}

Önerilen eğitim cüzdanı uygulaması önemli ve gizlilik gerektiren veriler barındıracağı için herkese açık olmayacak şekilde özel bir blokzinciri üzerinde çalıştırılacaktır. Özel blokzinciri sistemlerinde katılımcı ekleme, katılımcıları denetleme, veri yazma ve verilere erişim yetkilerinin belirlenmesi gibi işlerin bir kurul ya da grup tarafından yönetilmesi gerekmektedir. Önerilen uygulama üniversiteler, sürekli eğitim merkezleri, halk eğitim merkezleri, özel kurs ve sertifika merkezleri gibi eğitim kurumlarının özel blokzincirine katılabilmesine olanak sağlamaktadır. Kurul tarafından zincire katılımı onaylanan eğitim kurumları öğrencilere ait ders kredisi, sertifika, başarı belgesi, proje notu gibi bilgileri blokzincirine aktarabilmekte ve blokzinciri üzerinde veri sağlayıcı, veri deposu ve veri doğrulayıcı olarak görev yapmaktadır. Bu alanda yapılan çalışmalardan farklı olarak zincire katılmak isteyen eğitim kurumu bir blokzinciri düğümü oluşturup, kendi eğitim uygulaması ile blokzinciri dügümü arasındaki entegrasyonu sağlayabilecektir. Gerekli entegrasyonlar yapıldıktan sonra bir kurum tarafından kaydedilen bir öğrenciye ait etkinlik bilgisi tüm kurumlar ve ilgili öğrenci tarafından görülebilecektir. Bu sayede hem eğitim kurumları başvuru ya da özel şart gerektiren durumlarda öğrencilerin hazırbulunuşluk düzeyleri hakkında bilgi sahibi olabilecek hem de öğrenciler farklı kurumlardaki eğitim etkinliklerine erişebilecek ve doğrulama amacıyla kullanabilecektir.

Geliştirilen uygulamanın hayata geçirilebilmesi için katılımcı eğitim kurumları tarafından blokzincirine aktarılacak öğrenci etkinliklerinin ve bu verilere erişimleri denetleyen kuralların belirlenmesi gerekmektedir. Belirlenen kurallar çerçevesinde katılımcı her bir eğitim kurumuna blokzinciri sistemi kurulmalı ve kurulan sistemler ortak bir zincire bağlanmalıdır. Daha sonra kurulumu yapılan blokzinciri uygulamaları ile kurumların bilgi sistemleri arasındaki entegrasyonun 
yapılması gerekmektedir. Son olarak ise öğrenci verilerinin gerekli adımlarda blokzincirine aktarılması ve blokzincirinden öğrenci verisi sorgulamaya imkân veren arayüzler oluşturulmalıdır. Bahsedilen bu adımların daha iyi anlaşılması aşağıdaki bölümlerde ayrıntılı bilgi verilmiştir.

\section{MultiChain}

$\mathrm{Bu}$ çalışmada blokzinciri sistemi olarak MultiChain uygulamasının tercih edilmesinde bu uygulamanın birçok programlama dili için API (Application Programming Interface) desteği, kullanım kolaylığı, performans ve dokümantasyon hizmeti gibi özellikleri etkili olmuştur. MultiChain izinli katılımcıların verilere erişimini yöneten özel bir blokzinciri sistemidir ("MultiChain I Open source blockchain platform," n.d.). Sadece kayıtlı katılımcılar zincirdeki blokları okuma ve yazma erişimine sahiptir. MultiChain çoklu varlık yönetimi ile beraber data stream (veri yayını) hizmeti de sunmaktadır. Data stream, tüm zincirden izole edilmiş ayrı izinlere sahip NoSQL tarzında bir veritabanı olarak düşünülebilir. Data stream üzerinde metin, json verisi ya da dosya saklanabilmektedir. Veri boyutu olarak küçük bir metin parçası ya da 64 MB boyutunda bir dosya ile işlem yapılabilmektedir. Abadi, Ellul ve Azzopardi (2018) alanyazında blokzinciri konulu uygulama içeren çalışmaları incelemiş ve MultiChain uygulamasının en çok tercih edilen uygulamalardan biri olduğunu ifade etmiştir.

\section{Blokzinciri Kurulumu}

Sunulan örnek uygulama için S1, S2 ve S3 olarak 3 adet sunucu kullanılmıştır. Windows 10 işletim sistemine sahip bu sunucularda Intel Xeon $2.40 \mathrm{GHz}$ işlemci ve 32 GB bellek bulunmaktadır. Her sunucuya MultiChain uygulaması yüklenmiş ve Şekil 6'da görüldüğü gibi S1 sunucusunda project1 adlı zincir oluşturulmuş ve yayımlanmıştır.

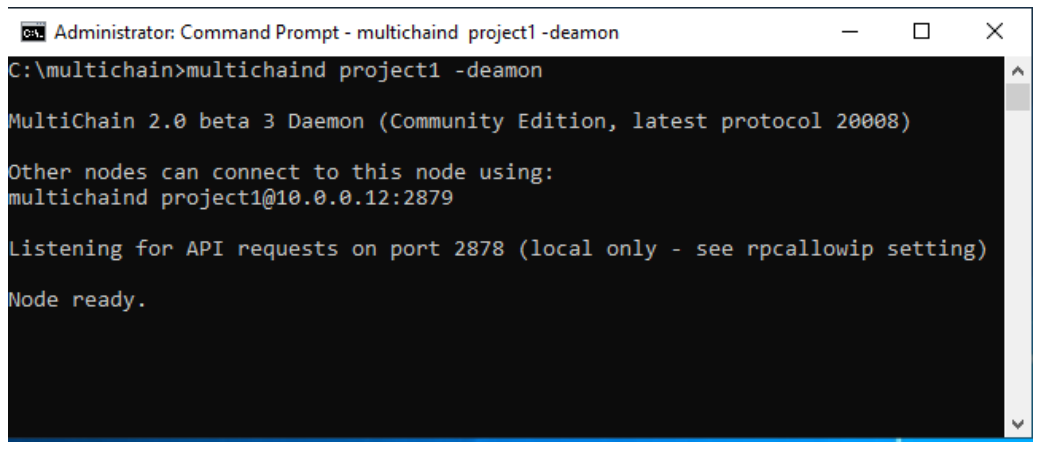

Şekil 6. Multichain ile Zincir Oluşturma

MultiChain özel bir blokzinciri sistemi olduğu için üzerinde yayımlanmış bir zincire bağlanmak, veri okumak ve veri kaydetmek için ip adresi ve port numaraları için güvenlik duvarında izin verilmesi gerekmektedir. Gerekli izinler sağlandıktan sonra 10.0.0.35 ip adresine sahip S2 sunucusunun, 10.0.0.12:2879 ip adresi ve portu ile S1 sunucusunda kurulan project1 isimli zincire bağlanabilmiştir. Şekil 7'de görüldüğü gibi S2 sunucusu artık blokzincirin bir katılımcısı olmuştur ve kendi üzerinden de zincirin yayımlanmasını sağlayabilmektedir. S2 sunucusu zincire bağlandıktan 
sonra veri senkronizasyonu sağlanır ve project1 adlı zincirin yöneticilerinden biri olur. Örneğin, S1 sunucusu sistemden çıarsa, S2 gibi diğer katılımcı sunucular project1 adlı zinciri kullanmaya devam edebilir.

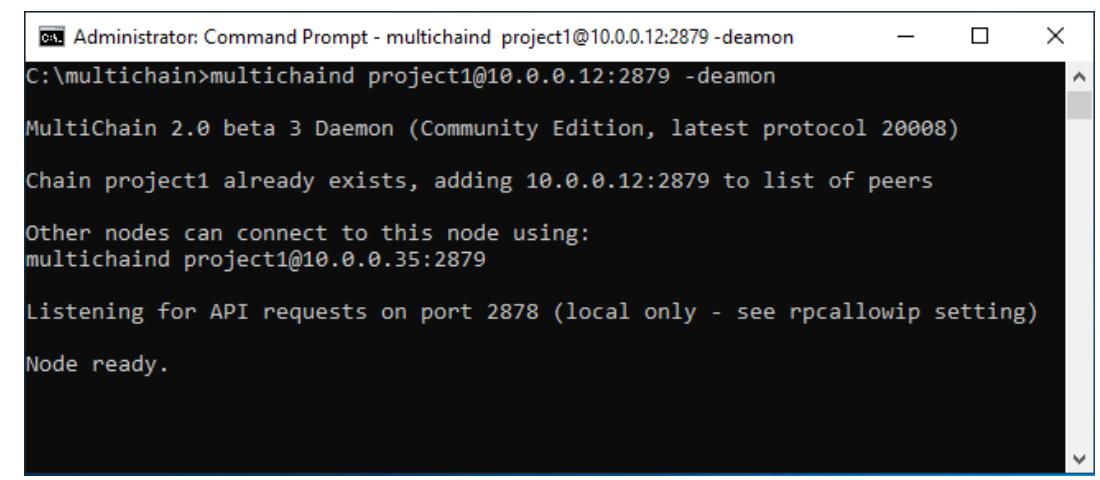

Şekil 7. Multichain ile Zincir Oluşturma

MultiChain geliştiriciler için blokzinciri sistemi üzerindeki veri hareketlerinin web tabanlı olarak görüntülenmesini sağlayan MultiChain Explorer uygulamasını sunmaktadır. Bu uygulama sayesinde kurulan zincir anlık olarak takip edilebilmektedir. Şekil 5, üç düğümün project1 adlı zincire katıldığını belirten MultiChain Explorer web sayfasının ekran görüntüsünü göstermektedir. Şekilde görüldüğü gibi, project1 adlı zincir 10.0.0.12 ip adresi ve 2879 numaralı bağlantı noktası ile sunucu tarafından başlatılmıştır. Daha sonra 10.0.0.35 ve 10.0.0.52 IP adresleri olan dügü̈mler bu zincire bağlanmaktadır.

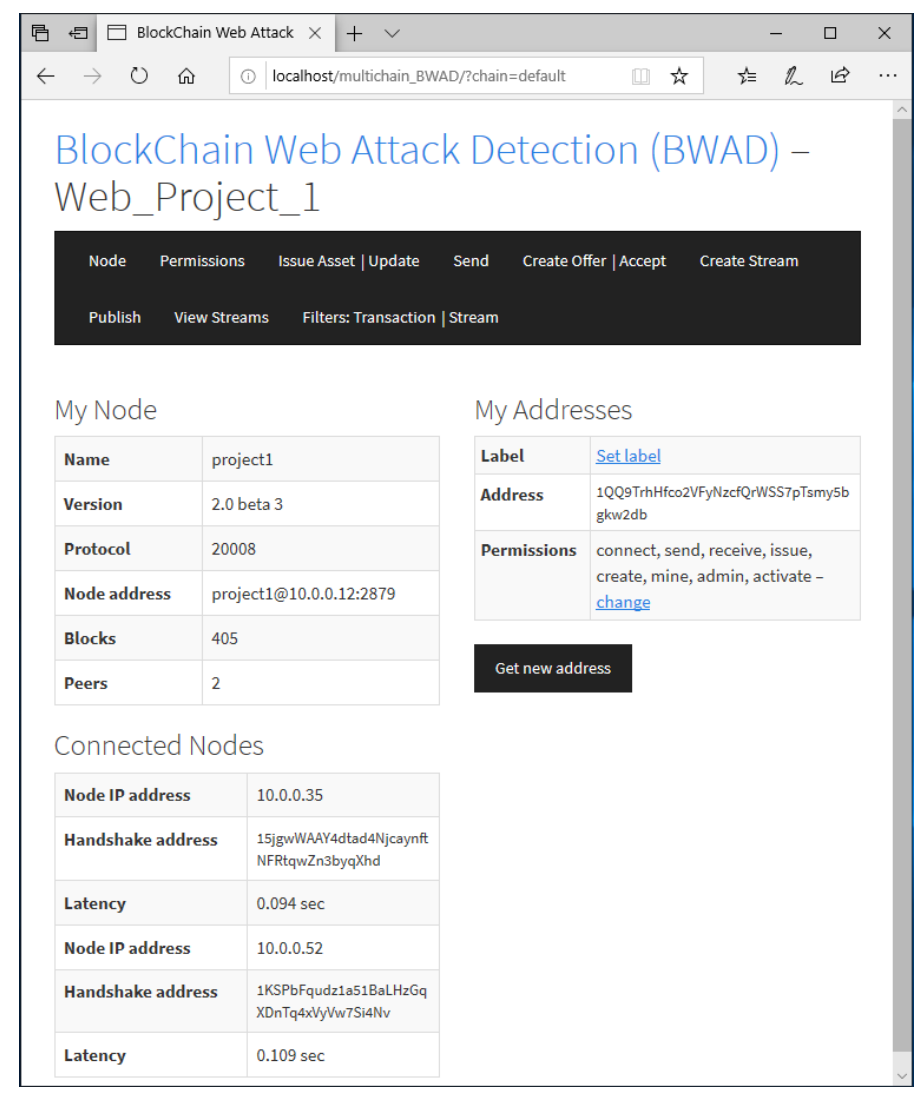

Şekil 8. Multichain Explorer Uygulamasına Ait Ekran Görüntüsü 
Şekil 8'deki MultiChain Explorer uygulamasına ait ekran görüntüsünde 10.0.0.12 ip adresi ve 2879 port numaralı bağlantı üzerinden başlatılan zincire 10.0.0.35 ve 10.0.0.52 ip adresli sunucuların bağlandığı görülmektedir.

$\mathrm{Bu}$ çalışmada blokzinciri şeffaf, değiştirilemez ve dağıtık yapıda bir veritabanı olarak düşünülmüştür. Multichain tarafından sunulan data stream yapısı, performans ve veri depolama seçenekleri bakımından bu amaç için uygun görülmüştür. Öğrencilerin eğitim etkinliklerinin saklanacağı "egitim_cuzdani" adında bir data stream oluşturulmuş ve katılımcı sunucuların erişimi için gerekli izinler verilmiştir. Şekil 9'da MultiChain Explorer uygulaması üzerinde "egitim_cuzdani" adında bir data stream yapısına ait bir ekran görüntüsü bulunmaktadır. Şekilde görüldüğü gibi öğrencilerin etkinliklerine ait bilgiler bu yapı üzerinde json formatında saklanabilmektedir.

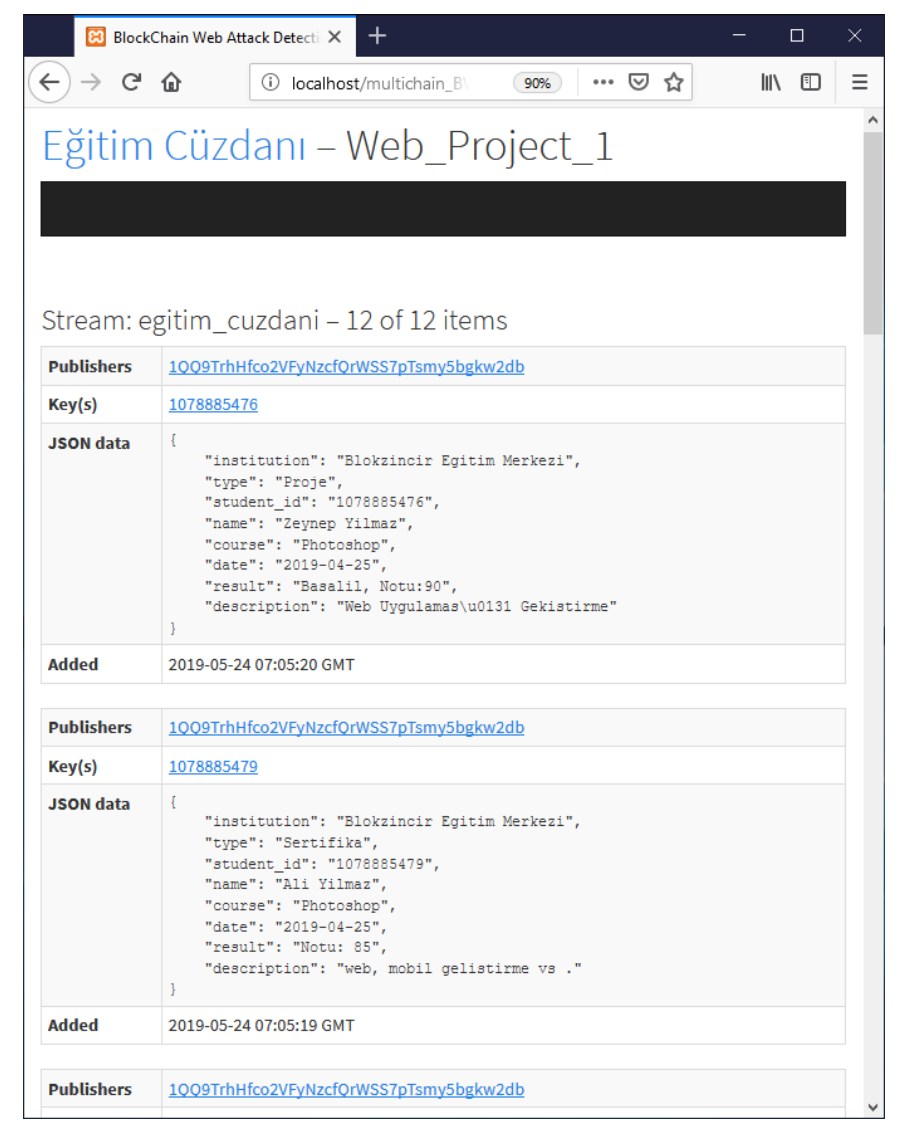

Şekil 9. "Egitim_Cuzdani” Adlı Data Stream

\section{Ĕ̆itim Cüzdanı Uygulaması}

Katılımcı sunuculara MultiChain uygulaması ile blokzinciri kurulumu ve gerekli yetkilendirmeleri yapıldıktan sonra bu sunucularda bulunan eğitim uygulamalarının kurulan blokzincirine bağlantısı sağlanmalıdır. Bu bağlantı için MultiChain tarafından geliştiriciler için sunulan API'ler kullanılmaktadır. Farklı eğitim kurumlarının öğrencilere ait eğitim etkinliklerini blokzinciri üzerinde paylaşılmasını sağlayan eğitim cüzdanı uygulamasının yapısı Şekil 10'da gösterilmiştir. Şekilde 3 adet uygulama sunucusu ve 3 adet blokzincir düğümü görülmektedir. Şekle göre her bir 
uygulama sunucusu için kendi üzerine ya da erişip yönetebileceği başka bir sunucuya bir blokzinciri düğümü oluşturulmuştur. Kurulan dügü̈mler de birbiri ile bağlanarak blokzinciri sistemini meydana getirmiştir. Örnek uygulama ortamı 3 adet sunucu ile sınırlandırılmıştır, gerekli mutabakat sağlandı̆̆ı durumda katılımcı sayısını arttırmak mümkündür.

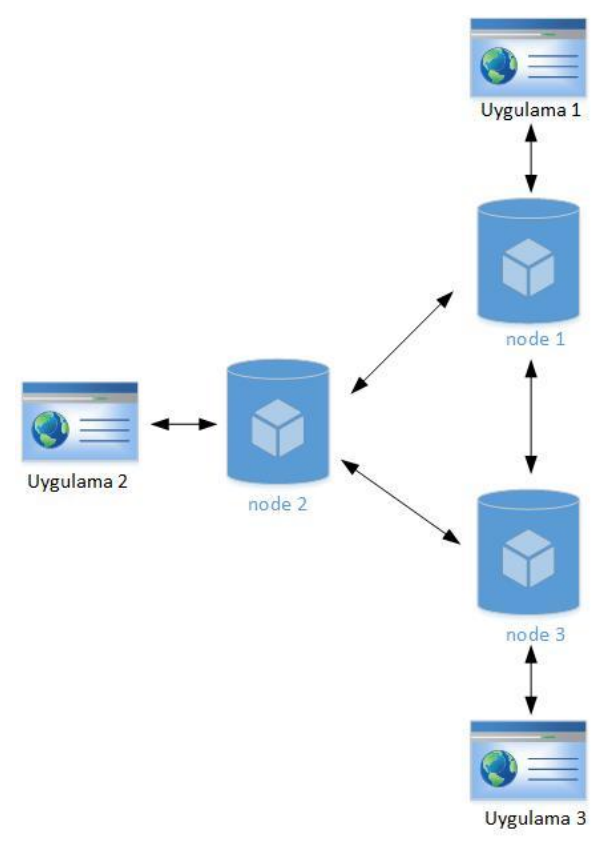

Şekil 10. Eğitim Cüzdanı Uygulamasının Genel Yapısı

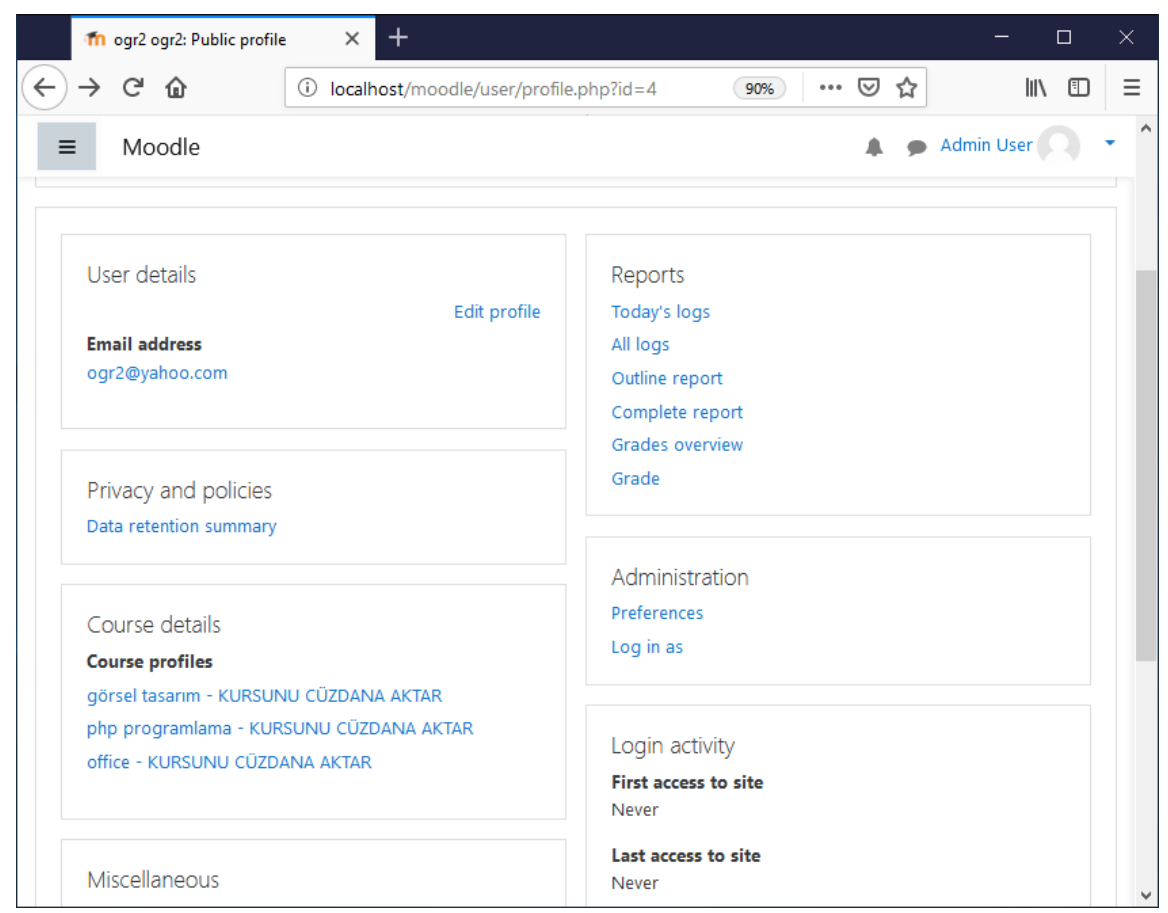

Şekil 11. Moodle Uygulamasına Ait Ekran Görüntüsü

Sunulan bu uygulama kapsamında S1 sunucuna Moodle e-öğrenme uygulaması kurulmuş ve blokzinciri sistemine entegrasyonu sağlanmıştır. Moodle açık kaynak kodlu bir uygulama olduğu için Multichain API'leri aracıllğıyla istenildiği takdirde tamamlanan ders, quiz sonuçları, sınav sonuçları, 
ödevler gibi eğitim etkinliklerinin blokzinciri ortamına aktarılması mümkün olmaktadır. Bu çalışmada Moodle uygulaması üzerinde öğrencilerin aldıkları derslerin blokzinciri ortamına aktarılması sağlanmıştır. Şekil 11'de Moodle uygulamasında bir öğrencinin profil sayfası görülmektedir. Bu ekrandaki derslerim alanında öğrencinin aldığı derslerin yanına "cüzdana aktar" linki yerleştirilmiş ve ilgili öğrencinin kimlik ya da cüzdan numarası ile birlikte ilgili dersin bilgilerini json formatında blokzincirine aktarma imkânı sağlanmıştır.

Moodle gibi bir uygulamaya ek olarak katılımcı eğitim kurumlarında farklı yapılarda bilgi sistemleri olabileceği düşünülerek S2 sunucusuna bir sertifika yönetim uygulaması için blokzinciri ortamına sertifika yükleme senaryosuna ilişkin bir uygulama geliştirilmiştir. Bir sertifika yönetimi uygulamasında ya da herhangi bir eğitim uygulamasında Şekil 12'deki gibi öğrenci etkinliklerinin listelendiği bir ekran bulunmaktadır. Bu ekranda bulunan "cüzdana aktar" linki aracılığıyla ilgili eğitim etkinliğine ait bilgileri blokzincirine aktarılabilecektir.

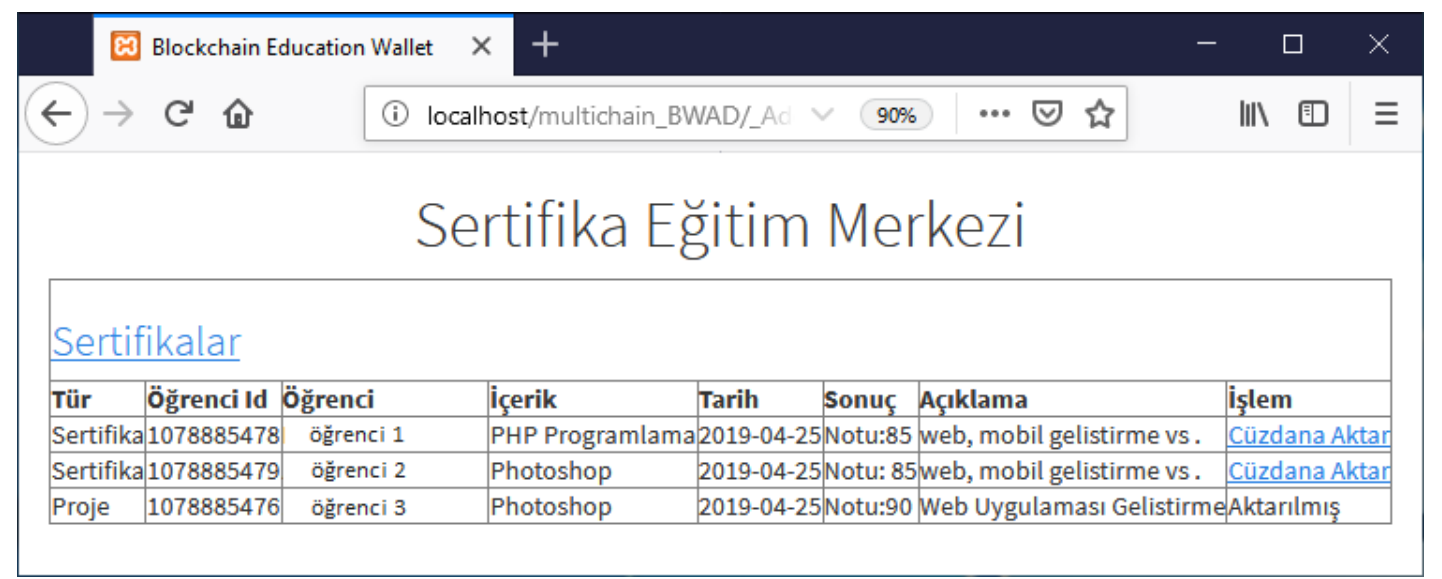

\section{Şekil 12. Eğitim Etkinlikleri Listeleme Ekranı}

$\mathrm{Bu}$ şekilde çeşitli eğitim uygulamaları üzerinden blokzincirine aktarılan öğrenci etkinlikleri daha sonra öğrencilerin kimlik numarası ya da anonim olarak belirlenmiş bir blokzinciri adresi ile sorgulanabilmektedir. Böylece blokzinciri üzerinde öğrencilerin eğitim etkinliklerinin bulunduğu eğitim cüzdanı oluşturulmuştur. Şekil 13'te görülen eğitim cüzdanı sorgulama ekranı sayesinde öğrenciler kendilerine ait etkinlikleri sorgulayabilmektedir. Ayrıca eğitim kurumları da öğrencilerin hazırbulunuşluk seviyelerini belirlemek amacıyla bu sorgulamaları yapabilmektedir. Bu bölümde sunulan eğitim cüzdanı uygulamasının örnek uygulaması hakkında ayrıntılı bilgi verilmiştir. Eğitim cüzdanı uygulaması sayesinde veri paylaşımı ve teknik konularda anlaşma sağlayan eğitim kurumları arasında öğrencilere ait eğitim etkinliklerinin blokzinciri üzerinde paylaşılmasına ve daha sonra eğitim kurumları ve öğrenciler tarafından sorgulama yapılmasına olanak sağlanmıştır. 


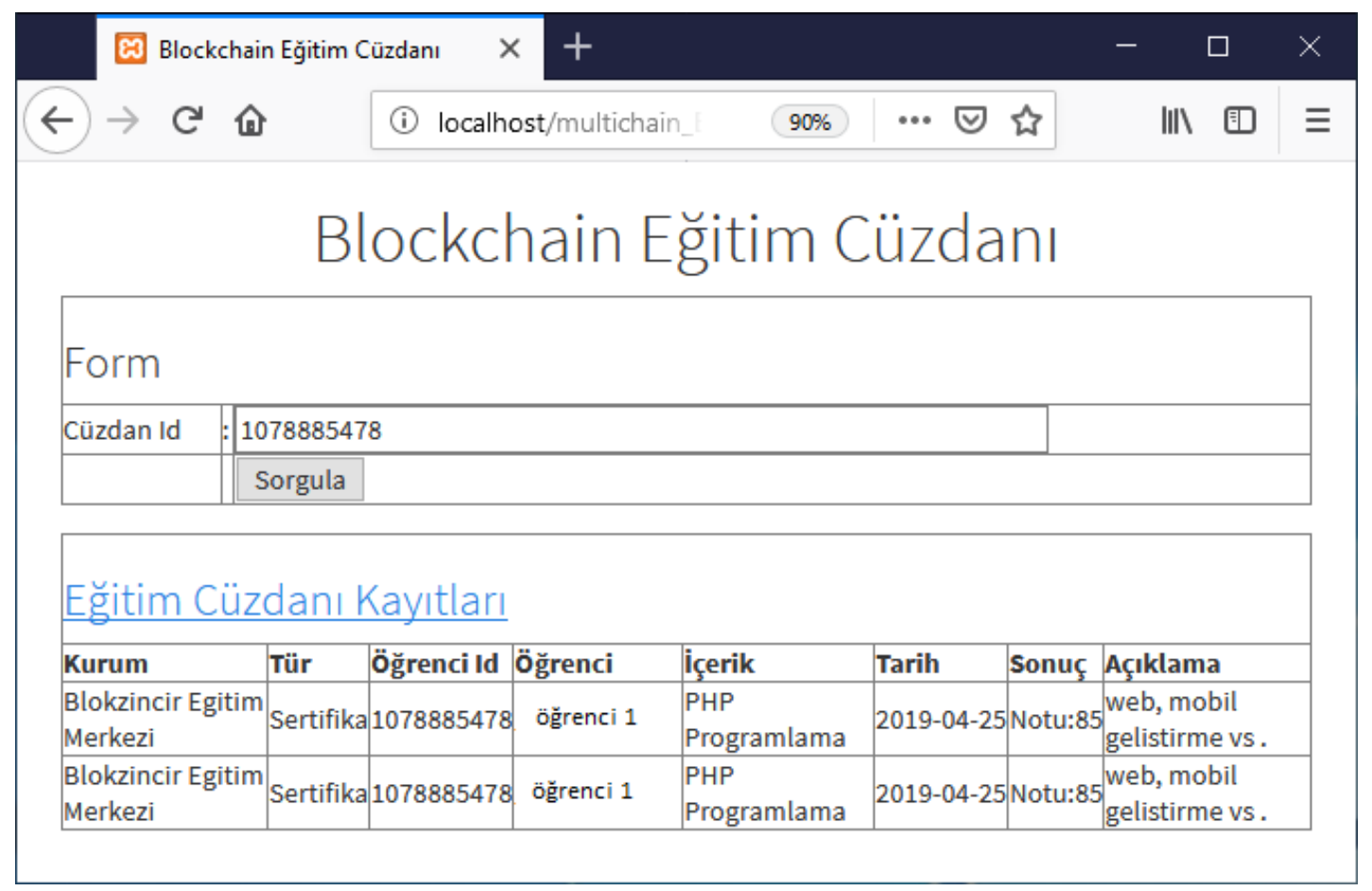

Şekil 13. Eğitim Cüzdanı Sorgulama Ekranı

\section{Sonuç}

Son yıllarda popüler hâle gelen merkeziyetçi olmayan dağıtık ve şeffaf yapısı sayesinde birçok alanda hayatı kolaylaştıran çözümler sunan blokzinciri teknolojisinin eğitim alanında da kullanımına rastlamak mümkündür. Literatürde ders kredisi ve diploma bilgilerinin blokzinciri üzerinde tutulmasına ilişkin sınırlı sayıda çalışma bulunmaktadır. Günümüzde eğitim kurumları veri paylaşımı konusunda güven sorunu yaşamaktadır ve bunun sonucu olarak da birbirleri ile sağlıklı ve verimli bir veri alışverişi yapılamamaktadır. Blokzincirinin en temel özelliği merkezi yapıların ve üçüncü taraf uygulamaların devreden çıkarılarak paydaşların birbirine güvenmesinin sağlanmasıdır. Blokzinciri ağında bulunan paydaşlar hem veri sağlayıcısı hem veri deposu hem de veri doğrulayıcı olarak görev yapmaktadır. Blokzinciri sayesinde eğitim kurumları arasında güvenli bir veri paylaşımı ortamı sunulabilmek mümkün olmaktadır.

Bu çalışmada eğitim kurumları arasında bir mutabakat sağlanması durumunda kurs, sınav sonucu, quiz sonucu, proje, ödev, seminer ve sertifika vb. eğitim etkinliklerinin blokzinciri üzerinde tutulmasını sağlayan bir uygulama geliştirilmiştir. Eğitim Cüzdanı adı verilen bu uygulama herhangi bir kısıtlama olmadan her türlü eğitim etkinliğinin blokzincirinde paylaşılması sayesinde öğrencilerin eğitim kurumlarından bağımsız olarak bir eğitim portföyü oluşturmasını ve eğitim kurumlarının öğrencilerin hazırbulunuşluk durumları hakkında bilgi edinmesini sağlamaktadır.

Blokzinciri teknolojisi yapısı gereği yazılım, donanım, ağ ve kriptoloji konularını ile ilgilidir ve çalışma mantı̆̆ının anlaşılması, genel yapısı, kurulumu ve yönetilmesi teknik bilgisi çok iyi olmayan 
araştırmacılara karmaşık gelebilmektedir. Çalışmada blokzinciri hakkında ayrıntılı bilgiye yer verilmiş ve eğitim alanında yapılmış çalışmalardan bahsedilmiştir. Örnek uygulama kapsamında blokzincirine katılacak eğitim kurumları için blokzinciri sisteminin kurulumu, kurulan blokzincirleri düğümlerinin birbirine bağlanması, kurumların bilgi sistemlerinin blokzinciri sistemi ile entegrasyonunun sağlanması konuları işlenmiştir. Bu konuların teknik bilgisi çok iyi olmayan araştırmacılar tarafından da anlaşılabilmesi için yapılan işlemler adım adım açıklanmış ve bu işlemlere ilişkin ekran görüntülerine yer verilmiştir. Bu çalışmanın eğitim alanında çalışan araştırmacılar için blokzinciri teknolojinin daha iyi anlaşılmasını sağlayacağı ve gelecekte yapılacak benzer çalışmalar için öncülük edeceği düşünülmektedir.

Önerilen uygulamanın hayata geçirilebilmesi ve başarılı bir şekilde yönetilebilmesi için eğitim kurumlarının sahip oldukları, ihtiyaç duydukları ve elde etmekte zorlandıkları verilerin belirlenmesi ve analiz edilmesi büyük fayda sağlayacaktır. Özel blokzincirinin yönetilmesi için gerekli kurulun da katılımcı eğitim kurumları tarafından belirlenmesi isabetli olacaktır. Eğitim cüzdanı uygulamasının yaygınlaşması için uygulamanın kuralları, sağladığı avantajlar ve teknik bilgilerin eğitim kurumlarına tanıtılması yoluyla bu kurumların eğitim cüzdanı uygulamasına katılımlarının teşvik edilmesi olumlu etki yaratacaktır. Uygulamanın yaygınlaşması sonrasında elde edilen veri havuzu, veri madenciliği, büyük veri, yapay zekâ, makine öğrenmesi gibi teknolojilerin kullanımı sayesinde faydalı birçok çalışmada kullanılabilir. Millî eğitim Bakanlığı, Yüksek Öğretim Kurumu, E-devlet Kapısı gibi kurumlar ile veri paylaşımı hem bu kurumlar hem de Eğitim Cüzdanı uygulaması için büyük kolaylıklar sağlayabilir.

\section{Kaynaklar}

Abadi, F. A., Ellul, J. \& G. Azzopardi (2018). The Blockchain of Things, Beyond Bitcoin: A Systematic Review. 2018 IEEE International Conference on Internet of Things (iThings) and IEEE Green Computing and Communications (GreenCom) and IEEE Cyber, Physical and Social Computing (CPSCom) and IEEE Smart Data (SmartData), Canada, pp. 1666-1672, doi: 10.1109/Cybermatics_2018.2018.00278.

Anascavage, R., \& Davis, N. (2018). Blockchain Technology: A Literature Review. SSRN. https://doi.org/10.2139/ssrn.3173406.

Beck, R. (2018). Beyond Bitcoin: The Rise of Blockchain World. Computer, 51(2), 54-58. https://doi.org/10.1109/MC.2018.1451660.

Blockchain Demo. (2019, 14 Mayıs). Erişim adresi https://anders.com/blockchain/

Blockchain Distributed Ledger Market Size by Type, End-User. (2017). Erişim adresi https://www.alliedmarketresearch.com/blockchain-distributed-ledger-market. 
Burgess, K. (2015). The Promise of Bitcoin and the Blockchain. Consumers' Research Primary. Erişim adresi https://www.academia.edu/23117440/The_Promise_of_Bitcoin_and_the_Blockchain_A_ product_of.

Buterin, V. (2015). On Public and Private Blockchains. https://doi.org/10.1016/j.pop.2004.02.009.

Cai, Y., \& Zhu, D. (2016). Fraud detections for online businesses: a perspective from blockchain technology. Financial Innovation, 2(1), 20. https://doi.org/10.1186/s40854-016-0039-4.

Camilleri, A. F. (2017). Blockchain in Education. https://doi.org/10.2760/60649.

Cheng, J. C., Lee, N. Y., Chi, C., \& Chen, Y. H. (2018). Blockchain and smart contract for digital certificate. In Proceedings of 4th IEEE International Conference on Applied System Innovation 2018, ICASI 2018 (pp. 1046-1051). IEEE. https://doi.org/10.1109/ICASI.2018.8394455.

Chuen, D. L. K. (2015). Handbook of Digital Currency: Bitcoin, Innovation, Financial Instruments, and Big Data. https://doi.org/10.1016/C2014-0-01905-3.

Efanov, D., \& Roschin, P. (2018). The all-pervasiveness of the blockchain technology. Procedia Computer Science, 123, 116-121). https://doi.org/10.1016/j.procs.2018.01.019.

Gatteschi, V., Lamberti, F., Demartini, C., Pranteda, C., \& Santamaria, V. (2018). To Blockchain or Not to Blockchain: That Is the Question. IT Professional, 20(2), 62-74. https://doi.org/10.1109/MITP.2018.021921652.

Haber, S., \& Stornetta, W. S. (1991). How to time-stamp a digital document. Journal of Cryptology, 3(2), 99-111. https://doi.org/10.1007/BF00196791.

Huynh, T. T., Tru Huynh, T., Pham, D. K., \& Khoa Ngo, A. (2018). Issuing and Verifying Digital Certificates with Blockchain. In 2018 International Conference on Advanced Technologies for Communications (ATC), 332-336. IEEE. https://doi.org/10.1109/ATC.2018.8587428.

MultiChain I Open source blockchain platform. (t.y.). Erişim adresi https://www.multichain.com/

Nakamato, S. (2008). Bitcoin: A Peer-toPeer Electronic Cash System. Erişim adresi https://bitcoin.org/bitcoin.pdf.

Puthal, D., Malik, N., Mohanty, S. P., Kougianos, E., \& Das, G. (2018). Everything You Wanted to Know about the Blockchain: Its Promise, Components, Processes, and Problems. IEEE Consumer Electronics Magazine, 7(4), 6-14. https://doi.org/10.1109/MCE.2018.2816299.

Reyna, A., Martín, C., Chen, J., Soler, E., \& Díaz, M. (2018). On blockchain and its integration with IoT. Challenges and opportunities. Future Generation Computer Systems, 88, 173-190. https://doi.org/10.1016/j.future.2018.05.046.

Ripple. (t.y.). Erişim adresi https://ripple.com/. 
Sharples, M., De Roock, R., Ferguson, R., Gaved, M., Herodotou, C., Koh, E., Wong, H. (2016). Innovating Pedagogy 2016 Exploring new forms of teaching, learning and assessment, to guide educators and policy makers. Erişim adresi www.open.ac.uk/innovating.

Shen, H., \& Xiao, Y. (2018). Research on Online Quiz Scheme Based on Double-Layer Consortium Blockchain. In 2018 9th International Conference on Information Technology in Medicine and Education (ITME), 956-960. IEEE. https://doi.org/10.1109/ITME.2018.00213.

Swan, M. (2015). Blockchain: Blueprint for a New Economy. https://doi.org/10.1109/CANDAR.2017.50.

Tanrıverdi, M., Uysal, M., \& Üstündağ, M. T. (2019). Blokzinciri Teknolojisi Nedir ? Ne Değildir ?: Alanyazın İncelemesi. Bilişim Teknolojileri Dergisi, 203-217. https://doi.org/10.17671/gazibtd.547122.

Turkanovic, M., Holbl, M., Kosic, K., Hericko, M., \& Kamisalic, A. (2018). EduCTX: A BlockchainBased Higher Education Credit Platform. IEEE Access, 6, 5112-5127. https://doi.org/10.1109/ACCESS.2018.2789929.

Wang, H., Chen, K., \& Xu, D. (2016). A maturity model for blockchain adoption. Financial Innovation, 2(1), 12. https://doi.org/10.1186/s40854-016-0031-z.

Wood, D. G. (2014). Ethereum: a Secure Decentralised Generalised Transaction Ledger. Erişim adresi https://www.semanticscholar.org/paper/Ethereum\%3A-a-Secure-Decentralised-GeneralisedLedger-Wood/79ee330676c159caf5dce2b2e004a76f966be126.

Yli-Huumo, J., Ko, D., Choi, S., Park, S., \& Smolander, K. (2016). Where Is Current Research on Blockchain Technology?-A Systematic Review. PLOS ONE, 11(10). https://doi.org/10.1371/journal.pone.0163477.

Zhao, J. L., Fan, S., \& Yan, J. (2016). Overview of business innovations and research opportunities in blockchain and introduction to the special issue. Financial Innovation, 2(1), 28. https://doi.org/10.1186/s40854-016-0049-2.

\section{Extended Summary}

\section{Educational Wallet for Students: Sharing of Students' Education Activities on Blockchain}

Blockchain technology, which entered our lives with crypto coins for the first time, has been receiving great attention recently from the media, organizations, and researchers. Due to its distributed, transparent, and reliable structure, people and organizations can share their data in a transparent and secure manner without the need for third-party intermediaries. In this way, many blockchain applications have been developed which make life easier in different fields. In this study, an application has been developed regarding the establishment of a blockchain system among 
education institutions providing services such as formal education, distance education, and certificate education.

Since 2016 and 2017, the concept of blockchain has become popular, and there has been a significant increase in the number of researches and applications on blockchain. There are studies on blockchain offering effective solutions in areas such as finance, public services, health, and supply chain. In the report "Innovating Pedagogy 2016" published by Open University, it is stated that the use of blockchain in the education field will become widespread in more than four years, and educational contents, course credits, and certificate information can be stored and shared on the blockchain. In a report entitled "Blockchain in Education" published in 2017, the European Commission proposed scenarios for the use of blockchain technology in areas such as certification, lifelong learning, tuition fees, and scholarship payments to students. Thus, if the documents such as certificates, diplomas, and transcripts are stored on the blockchain, the loss and destruction of these documents can be prevented. In this way, students and third parties will be able to verify a certificate via the blockchain.

There are a limited number of studies in the literature on keeping course credit and diploma information on the blockchain. Today, educational institutions have a problem of trust in data sharing, and as a result, a healthy and efficient data exchange cannot be made with each other. The main feature of the blockchain is disabling centralized structures and third-party applications, and enabling stakeholders to trust each other. The stakeholders in the blockchain network act as data providers, data repositories, and data validators. Thanks to the blockchain, it is possible to provide a secure datasharing environment between educational institutions.

In order to implement the developed application, the student activities to be transferred to the blockchain by the participating educational institutions and the rules governing the access to this data should be determined. Within the framework of these rules, the establishment of a blockchain application for each educational institution and the established practices should be linked to a joint chain. Afterwards, an integration between the blockchain applications and the information systems of the institutions is required. Finally, interfaces that allow student data to be transferred to the blockchain in the necessary steps and query student data from the blockchain should be created.

MultiChain, which is a special blockchain system that manages the access of authorized participants to data, has been preferred, offering API (Application Programming Interface) support, ease of use, performance, and documentation services for many programming languages. For the example application, three servers are used as S1, S2, and S3. The MultiChain application is installed on each server, and the chain named project1 is created and published on the S1 server. Since MultiChain is a private blockchain system, it is necessary to be allowed on the firewall to connect to a published chain, to read and record data, for IP address and port numbers. After the necessary 
permissions were obtained, the S2 server could be connected to the chain named project1 established on the S1 server with the specified IP address and port. The S2 server is now a participant in the blockchain and can also stream the chain through itself. After the S2 server is connected to the chain, data synchronization is achieved and becomes one of the managers of the chain named project1. For example, if server S1 exits, other participating servers, such as S2, may continue to use the chain named project1. MultiChain provides web-based monitoring of data movements on the blockchain system for developers. With the data stream structure provided by Multichain, a data stream named "egitim_cuzdani" was created to store the educational activities of the students, and the necessary permissions were granted for the access of the participating servers. After the installation of the blockchain with the MultiChain application and necessary authorization to the participating servers, the educational applications on these servers were connected to the established blockchain by the APIs provided by MultiChain for developers. The educational wallet application, which allows different educational institutions to share the educational activities of the students on the blockchain, is limited to three servers. It is possible to increase the number of participants if the necessary agreement is reached. Within the scope of this application, the Moodle e-learning application was installed on the S1 server, and integration to the blockchain system was ensured. Since Moodle is an open-source application, it is possible to transfer training activities such as courses, quizzes, exam results, and homework completed to the blockchain environment via Multichain APIs. In the Moodle application implemented in this study, students can transfer the course information they have taken in JSON format to blockchain along with ID or wallet number. In this way, the student activities that are transferred to the blockchain through various educational applications can then be queried with the student's identification number or an anonymously determined blockchain address. Thus, an educational wallet containing the educational activities of the students on the blockchain was created. In this way, students can question their own activities, and educational institutions can make these inquiries in order to determine the readiness levels of the students.

In this study, an application has been developed to keep educational activities such as courses, exam results, quiz results, projects, homework, seminars, and certificates on the blockchain, in case an agreement is reached between educational institutions. This application, called Education Wallet enables students to create a portfolio of education independently from educational institutions. Also, educational institutions can obtain information about the readiness of students by means of sharing all kinds of educational activities in the blockchain without any restrictions and make use of these data for future training programs. Within the scope of the exemplary application, the establishment of the blockchain system for the educational institutions to be included in the blockchain, the connection of 
the established blockchains to each other, and the integration of the information systems of the institutions with the blockchain system were included.

Blockchain technology, due to its nature, is related to software, hardware, network, and cryptology technologies, and understanding the general structure, installation, and management can be complicated for researchers who do not have very good technical knowledge. In this study, detailed information about blockchain technology is included, and studies in the field of education are mentioned. The steps taken regarding the blockchain installation are explained, and screenshots are included. It is thought that this study will provide a better understanding of blockchain technology for researchers working in the field of education and will lead the way for similar studies in the future.

In order to implement the proposed application and manage it successfully, it will be of great benefit to identify and analyze the data that educational institutions have, need, and have difficulty in obtaining. For the widespread use of the education wallet, encouraging educational institutions to participate in the education wallet application by introducing the rules of the application, the advantages it provides, and technical information to the educational institutions will have a positive effect. The data pool obtained after the widespread use of the application can be used in many useful studies thanks to the use of technologies such as data mining, big data, artificial intelligence, and machine learning. Data sharing with government institutions related to education can provide a great convenience for both these institutions and the application of the Education Wallet. 